\title{
Tolerance of Anaerobic Bacteria to Chlorinated Solvents
}

\author{
JOANnA C. KOENIG ${ }^{1 *}$, KATHRIn D. GROISSMEIER ${ }^{2}$, and MiKE J. MANEFIELD ${ }^{1}$ \\ ${ }^{1}$ Centre for Marine Bioinnovation, School of Biotechnology and Biomolecular Sciences, University of New South Wales, Sydney, \\ Australia; and ${ }^{2}$ Helmholtz Institute of Groundwater Ecology, Ingolstaedter Landstrasse 1, D-85764, Neuherberg, Germany
}

(Received August 27, 2013 -Accepted November 8, 2013 -Published online January 17, 2014)

The aim of this research was to evaluate the effects of four chlorinated aliphatic hydrocarbons (CAHs), perchloroethene (PCE), carbon tetrachloride (CT), chloroform (CF) and 1,2-dichloroethane (1,2-DCA), on the growth of eight anaerobic bacteria: four fermentative species (Escherichia coli, Klebsiella sp., Clostridium sp. and Paenibacillus sp.) and four respiring species (Pseudomonas aeruginosa, Geobacter sulfurreducens, Shewanella oneidensis and Desulfovibrio vulgaris). Effective concentrations of solvents which inhibited growth rates by $50 \%\left(\mathrm{EC}_{50}\right)$ were determined. The octanol-water partition coefficient or $\log \mathrm{P}_{\mathrm{o} / \mathrm{w}}$ of a CAH proved a generally satisfactory measure of its toxicity. Most species tolerated approximately 3 -fold and 10-fold higher concentrations of the two relatively more polar CAHs CF and 1,2-DCA, respectively, than the two relatively less polar compounds PCE and $\mathrm{CT}$. $\mathrm{EC}_{50}$ values correlated well with growth rates observed in solvent-free cultures, with fast-growing organisms displaying higher tolerance levels. Overall, fermentative bacteria were more tolerant to CAHs than respiring species, with iron- and sulfate-reducing bacteria in particular appearing highly sensitive to CAHs. These data extend the current understanding of the impact of CAHs on a range of anaerobic bacteria, which will benefit the field of bioremediation.

Key words: solvent tolerance, chlorinated solvents, anaerobic bacteria, toxicity

Chlorinated aliphatic hydrocarbons (CAHs) contaminate many soil and groundwater sites worldwide. Due to their significant hydrophobicity, resistance to degradation and toxicity, they create long-term sources of pollution and are the target of remediation efforts (8). Bioremediation, a technology relying on bacteria to degrade contaminants, is a proven treatment option for $\mathrm{CAH}$ remediation $(2,52)$. Highly chlorinated CAHs such as perchloroethene (PCE) and carbon tetrachloride (CT) are not susceptible to degradation by aerobic bacteria, but can be detoxified through the action of many types of anaerobic bacteria $(21,38)$. These include organohalide respiring bacteria (ORB), iron-, sulfate- and nitrate-reducing bacteria, and fermenters $(13,15,36,43$, 48). These bacteria can either degrade CAHs enzymatically and derive energy in this way or mediate $\mathrm{CAH}$ removal cometabolically.

One important limitation of microbially mediated $\mathrm{CAH}$ degradation is the occurrence of toxic effects on bacteria. Being lipid-soluble solvents, CAHs partition in bacterial membranes, causing substantial damage to cells when present above certain concentrations (29). The magnitude of this toxicity depends on a solvent's physicochemical attributes combined with the ability of a particular bacterial species to mount responses to solvent stress. Tolerance mechanisms employed to withstand solvent stress include solvent degradation, modification of membrane and cell wall composition, and active solvent extrusion by efflux pumps (20, 46, 47). Tolerance varies between species, and $\mathrm{CAH}$ bioremediation strategies that employ bacteria selected for their superior tolerance to the target solvents are more likely to achieve successful rates and extents of remediation.

\footnotetext{
* Corresponding author. E-mail: j.koenig@unsw.edu.au; Tel: +6129385-8703; Fax: +612-9385-1779.
}

However, most knowledge concerning the solvent tolerance of bacteria has been accumulated through studies of aerobic bacteria. For example, it has been shown that the toxicity of a particular solvent is correlated with its hydrophobicity, given by its $\log \mathrm{P}_{\mathrm{o} / \mathrm{w}}$ value (28). $\log \mathrm{P}_{\mathrm{o} / \mathrm{w}}$, the logarithm of a solvent's partitioning in a standard octanol/ water two-phase system, represents the ratio of solvent concentrations in each of the two liquids:

$$
\log P_{o / w}=\log \left(\frac{[\text { solvent }]_{\text {octanol }}}{[\text { solvent }]_{\text {water }}}\right)
$$

High $\log \mathrm{P}_{\mathrm{o} / \mathrm{w}}$ solvents are more hydrophobic (or lipophilic) and those with $\operatorname{low} \log \mathrm{P}_{\mathrm{o} / \mathrm{w}}$ are more hydrophilic. Solvents with $\log \mathrm{P}_{\mathrm{o} / \mathrm{w}}$ of between 1 and 4 are thought to be especially toxic to bacteria, as they are water-miscible enough to be bioavailable and lipid-soluble enough to disrupt bacterial membranes and cause cell death (49). Numerous aerobic bacteria able to grow in the presence of free-phase solvents have now been isolated, a large proportion of which belong to the genera Pseudomonas, Bacillus and Rhodococcus $(27,29)$.

The same level of information is not available concerning anaerobic bacteria. Certain species such as Clostridium acetobutylicum and Zymomonas mobilis employed in the production of solvents and biofuels have been studied in detail $(10,45)$; however, very few data exist regarding the solvent tolerance of other anaerobic species important in $\mathrm{CAH}$ bioremediation settings. Because $\mathrm{CAH}$-contaminated environments such as soil and aquifers are often complex and inhabited by a variety of species, it is useful to not only understand how solvents influence the species targeted as the catalyst of remediation but also co-existing species which may modulate bioremediation outcomes through mutualism or competition. In this sense, a broad view of the 
solvent tolerance of different metabolic types of anaerobes is beneficial. While reports of solvent levels tolerated by ORB are available $(1,5,55)$, this is not the case for other metabolic types. Duldhardt et al. $(18,19)$ recently determined solvent tolerance levels for the iron reducer Geobacter sulfurreducens, the sulfate reducer Desulfococcus multivorans and the nitrate reducer Thauera aromatica with a number of hydrocarbons relevant to oil contamination; however, no CAHs were tested.

The present article focuses on the sensitivity of anaerobic bacteria to chlorinated solvents. The aim was to generate $\mathrm{EC}_{50}$ values for a diverse range of bacteria potentially relevant to $\mathrm{CAH}$ bioremediation. The impact of perchloroethene (PCE), carbon tetrachloride (CT), chloroform (CF) and 1,2-dichloroethane (1,2-DCA) on bacterial growth rates was assessed. These four CAHs were chosen as they are classified as priority pollutants (8) and are amenable to degradation by anaerobic bacteria $(16,24,39,40)$.

A broad range of bacteria was chosen based on their environmental origin, relevance to bioremediation, and presence in the existing solvent tolerance literature for ease of data comparison. Of the four fermentative bacteria selected, Escherichia coli was chosen due to its widespread use as a model organism for bacteria in general and the large body of literature concerning various aspects of its tolerance to xenobiotic compounds. Klebsiella sp. was chosen as a fast-growing fermenter and was isolated from a wastewater treatment plant, which potentially exposed it to a range of compounds and influenced its ability to tolerate solvents. Clostridium sp. and Paenibacillus sp. were isolated from a $\mathrm{CAH}$-contaminated site and were of particular interest since their long-term exposure to CAHs hypothetically affected their response to solvent stress. Of the four respiratory lineages examined, the nitrate reducer Pseudomonas aeruginosa was chosen because of the considerable amount of knowledge regarding the resistance of Pseudomonas spp. to organic solvents. The iron reducers Geobacter sulfurreducens and Shewanella oneidensis were chosen as representatives of ubiquitous respiring anaerobes with bioremediation potential, and finally the sulfate reducer Desulfovibrio vulgaris was selected as a representative of sulfate-reducing bacteria, also widespread in anaerobic environments and with potential applications as agents of bioremediation.

\section{Materials and Methods}

\section{Bacteria and culture conditions}

All bacteria included in this study were cultivated under conditions known to favor optimal growth in order to minimize the impact of growth-limiting factors other than CAHs. Escherichia coli strain K12 substrain W3110 and Pseudomonas aeruginosa strain PAO1 were obtained from the University of New South Wales culture collection. Both species were cultivated under $\mathrm{N}_{2}$ in Luria Bertani broth (LB), containing per L: $10.0 \mathrm{~g}$ tryptone, $5.0 \mathrm{~g}$ yeast extract and $10.0 \mathrm{~g} \mathrm{NaCl}$. For $P$. aeruginosa, $2.0 \mathrm{~g} \mathrm{~L}^{-1} \mathrm{NaNO}_{3}$ was added as this organism requires $\mathrm{NO}_{3}^{-}$as an electron acceptor in the absence of oxygen.

Klebsiella sp. strain SM1, Clostridium sp. strain BIP1 and Paenibacillus sp. strain BIP2 were isolated in our laboratory and deposited in the Belgian Co-ordinated Collection of Microorganism (BCCM) under the respective strain numbers LMG 26928, LMG 26929 and LMG 26926. Isolation and identification procedures are described below. These three bacteria were grown under $\mathrm{N}_{2}$ in half-concentrated Brain-Heart Infusion broth (Oxoid, Basingstoke, UK) containing, per L: $8.75 \mathrm{~g}$ beef heart infusion solids, $5.0 \mathrm{~g}$ proteose peptone, $1.0 \mathrm{~g}$ glucose, $2.5 \mathrm{~g} \mathrm{NaCl}$ and $1.25 \mathrm{~g} \mathrm{Na}_{2} \mathrm{HPO}_{4}$ and 0.4 $\mathrm{g} \mathrm{L}^{-1}$ cysteine- $\mathrm{HCl}$ as a reducing agent.

Geobacter sulfurreducens strain $12127^{\mathrm{T}}$ and Desulfovibrio vulgaris subsp. vulgaris strain 2119 were purchased from the German Collection of Microorganisms and Cell Cultures (DSMZ, Braunschweig, Germany). G. sulfurreducens was cultivated under $\mathrm{N}_{2}-\mathrm{CO}_{2}(80 / 20 \mathrm{v} / \mathrm{v})$ in the DSMZ-recommended defined medium DSM 826, with $10 \mathrm{mmol} \mathrm{L}^{-1}$ acetate as an electron donor and $50 \mathrm{mmol} \mathrm{L}^{-1}$ fumarate as an electron acceptor (http://www.dsmz.de, accessed 30/07/2013). Desulfovibrio vulgaris was cultivated under $\mathrm{N}_{2}-\mathrm{CO}_{2}$ in DSMZ medium 334, replacing the acetate with $10 \mathrm{mmol}$ $\mathrm{L}^{-1}$ lactate as an electron donor and adding $5 \mathrm{mmol} \mathrm{L}^{-1}$ sulfate as an electron acceptor. Shewanella oneidensis strain MR-1 was purchased from the American Type Culture Collection (ATCC strain 700550 ) and cultivated under $\mathrm{N}_{2}-\mathrm{CO}_{2}$ in a defined medium described in Löffler et al. (37) with $20 \mathrm{mmol} \mathrm{L}^{-1}$ lactate as an electron donor and $20 \mathrm{mmol} \mathrm{L}^{-1}$ fumarate as an electron acceptor.

\section{Isolation and identification of fermenting bacteria}

Three fermentative bacterial strains were isolated from two environmental sources, namely wastewater and groundwater from a CAH-contaminated site, in order to incorporate bacteria from polluted environments in the study and their response was compared to that of well-studied characterized strains.

Firstly, strain SM1 was isolated from activated sludge from the St Mary's Wastewater Treatment plant in Sydney, Australia, by spread-plating sludge onto R2A agar plates (Oxoid) and incubating aerobically at $30^{\circ} \mathrm{C}$. Secondly, strains BIP1 and BIP2 were isolated either by inoculating groundwater associated with a PCE/CT Dense Non-Aqueous Phase Liquid (DNAPL) sample from a CAHcontaminated site in Sydney, Australia, into defined anaerobic medium containing glucose (BIP1), or by spread-plating onto aerobic LB agar plates (BIP2). For species identification, colony PCRs were performed to amplify the $16 \mathrm{~S}$ rRNA gene with primers $27 \mathrm{~F}$ and $1492 \mathrm{R}$ (34). Thermal cycling was performed at $95^{\circ} \mathrm{C}$ for 5 min; this was followed by 30 cycles consisting of $94^{\circ} \mathrm{C}$ for $1 \mathrm{~min}$, $55^{\circ} \mathrm{C}$ for $30 \mathrm{~s}$, and $72^{\circ} \mathrm{C}$ for $1 \mathrm{~min}$. PCR products were purified using silica-membrane-based columns of the QIAquick PCR purification kit (Qiagen, Chadstone, Australia) according to the manufacturer's instructions and sequenced using an Applied Biosystems 3730 DNA Analyzer. Sequences 600-700 base-pairs in length (both forward and reverse for each strain) were matched against online NCBI nucleotide databases using the Megablast algorithm of the Basic Local Alignment Search Tool (BLAST) $(4,57)$. Uncultured and environmental sequences were excluded from searches in order to obtain most closely related known organisms.

\section{Solvent tolerance tests}

Solvent tolerance tests were carried out in $25 \mathrm{~mL}$ Hungate tubes containing $10 \mathrm{~mL}$ medium, capped with Teflon-lined rubber stoppers and sealed with aluminum crimp caps. Incubation temperatures were as follows: E. coli $30^{\circ} \mathrm{C}, P$. aeruginosa $37^{\circ} \mathrm{C}, S$. oneidensis $30^{\circ} \mathrm{C}$, Klebsiella sp. $26^{\circ} \mathrm{C}$, Paenibacillus sp. $30^{\circ} \mathrm{C}$, Clostridium $\mathrm{sp}$. $24^{\circ} \mathrm{C}$, G. sulfurreducens $30^{\circ} \mathrm{C}$ and D. vulgaris $30^{\circ} \mathrm{C}$. Each species was tested with PCE, CT, CF and 1,2-DCA, each at five different concentrations in triplicate. One set of control triplicates did not include any solvent and served as the benchmark for growth rate comparisons. Each species was tested with all four CAHs at the same time in order to minimize any variations between cultures used on different days.

Solvents were added to autoclaved tubes directly as the free phase or as dilute ethanolic stocks ( 1 to $100 \mu \mathrm{L}$ ). When ethanolic stocks were used, one set of triplicates was set up including the maximum ethanol concentration (analytical grade ethanol; Ajax Finechem, Sydney, Australia) used in order to control the effect of ethanol on growth. No differences were observed between no-solvent and 
ethanol-only controls. Tubes were left at room temperature overnight to allow for solvent equilibration between the aqueous phase and headspace before inoculation. Tests were initiated by inoculating exponentially growing parent cultures (5\% transfers). Growth was monitored by measuring optical density at $600 \mathrm{~nm}$ against medium blanks. Monitoring ceased as soon as the stationary phase was reached, which took between $5 \mathrm{~h}$ for fast-growing organisms such as Klebsiella sp. and $70 \mathrm{~h}$ for slow growers such as D. vulgaris.

\section{Mathematical treatment of data}

Actual solvent concentrations in the aqueous phase were calculated using Henry's constants for each temperature, aqueous and gas phase volumes and volumes of solvent added. For PCE, solvent concentrations above the maximum aqueous solubility of $0.9 \mathrm{mmol} \mathrm{L}^{-1}$ are nominal and do not reflect actual dissolved concentrations but rather indicate increasing amounts of free-phase PCE.

Specific growth rates $\mu\left(\mathrm{h}^{-1}\right)$ were determined by plotting the natural logarithm of $\mathrm{OD}_{600}$ at time " $t$ " $\left(\mathrm{X}_{\mathrm{t}}\right)$ over that at time " 0 " $\left(\mathrm{X}_{0}\right)$ versus time:

$$
\mu=\left[\ln \left(\frac{X_{t}}{X_{0}}\right)\right] \div t
$$

Time " 0 " was taken as the beginning of exponential growth. No differences in lag or exponential phase lengths were observed between no-solvent controls and solvent-containing cultures: bacteria consistently started and ceased growing at the same time and growth only varied in rate. Average specific growth rates were calculated for each set of triplicates and are expressed as percentages of the no-solvent controls' average growth rate $\mu_{0}$ set at $100 \%$. These percentages were plotted against solvent concentrations and the effective concentration causing a $50 \%$ decrease in growth rate $\left(\mathrm{EC}_{50}\right)$ was estimated by linear interpolation and in a few cases by extrapolation. Growth rates of zero were assigned to cultures where $\mathrm{OD}_{600}$ readings either decreased or did not increase above 0.04 during tests.

The fate of CAHs in bacterial cultures was checked by gas chromatography and flame ionization detection (GC-FID) as described elsewhere (33). The CAHs were never utilized as carbon sources by the bacteria and remained stable.

\section{Results}

This study included the isolation and identification of three fermentative bacterial strains from environmental sources. Following $30^{\circ} \mathrm{C}$ incubation of R2A agar plates on which 10 $\mu l$ activated sludge had been spread, a single colony was picked and inoculated into liquid aerobic LB medium. The purity of this isolate, named SM1, was confirmed by microscopic examination and by spread-plating. Partial sequences of strain SM1's 16S rRNA gene (DDBJ accession number AB858357) matched the 16S rRNA gene sequences of various strains of Klebsiella oxytoca with $100 \%$ similarity; hence, this bacterium is referred to as Klebsiella sp. strain SM1.

Following the inoculation of CAH-contaminated groundwater into anaerobic glucose medium, growth at $30^{\circ} \mathrm{C}$ was observed by increased turbidity and acid formation within one month. Small white colonies appeared in R2A agar roll tubes inoculated with this glucose-fermenting culture. Colonies were picked and inoculated into anaerobic liquid R2A medium. Culture purity was confirmed microscopically and by spreading onto R2A and LB agar plates, incubated both aerobically and in an anaerobic jar at $30^{\circ} \mathrm{C}$. The isolate, named BIP1, could not grow aerobically and formed large white colonies on anaerobic R2A agar plates only. It was identified as a member of the Clostridium genus by partial 16S rRNA gene analysis (DDJB accession number AB858358), most closely matching Clostridium sp. strain BL-26 (99.8\% similarity, GenBank accession number DQ196630.2).

The same groundwater collected above a CAH-DNAPL layer was spread onto LB plates which were incubated aerobically at $30^{\circ} \mathrm{C}$. A single colony was picked and re-streaked, then inoculated into both aerobic and anaerobic liquid LB medium. This isolate, named strain BIP2, was able to grow in both conditions and was characterized as a strain of Paenibacillus stellifer, its partial 16S rRNA gene sequence (DDJB accession number AB858359) most closely matching Paenibacillus stellifer strain Gt48 (99\% similarity, GenBank accession number GU321993.1). It is referred to hereafter as Paenibacillus sp. strain BIP2.

All eight anaerobic bacteria tested were negatively affected by the presence of CAHs in the growth medium, and solvent concentrations found to decrease their growth rates by half are reported in Fig. 1. All eight species were able to grow at $50 \%$ of no-solvent rates $\left(\mu_{0}\right)$ with $0.3 \mathrm{mmol} \mathrm{L}^{-1}$ PCE or more (Fig. 1A). Klebsiella sp. was the species most tolerant to PCE, and could still grow at $54 \%$ of $\mu_{0}$ at the maximum nominal concentration tested of $4.58 \mathrm{mmol} \mathrm{L} \mathrm{m}^{-1}$; hence, its $\mathrm{EC}_{50}$ value for PCE was estimated by extrapolation at 4.95 mmol $\mathrm{L}^{-1}$. Except for $S$. oneidensis, D. vulgaris and $G$. sulfurreducens, all bacteria had $\mathrm{EC}_{50}$ values for PCE above this solvent's maximum solubility of $0.9 \mathrm{mmol} \mathrm{L}^{-1}$ which means they were still able to grow at or above $50 \%$ of $\mu_{0}$ when PCE was present as a separate phase. Further increases in nominal PCE concentrations led to eventual complete inhibition of growth, indicating that free-phase PCE itself exerted toxic effects. S. oneidensis, D. vulgaris and $G$. sulfurreducens were affected by PCE below the point of free-phase appearance.

With CT (Fig. 1B), S. oneidensis, D. vulgaris and $G$. sulfurreducens were unable to grow even at the lowest levels tested of 80,80 and $30 \mu \mathrm{M}$, respectively. The other five species displayed $\mathrm{EC}_{50}$ values between 0.5 and $2.4 \mathrm{mmol} \mathrm{L}^{-1}$, corresponding to between 10 and $50 \%$ of CT's aqueous solubility of $5 \mathrm{mmol} \mathrm{L}^{-1}$. Paenibacillus sp., isolated from a CAH-contaminated site, was the organism most tolerant to $\mathrm{CT}$ with an $\mathrm{EC}_{50}$ value of $2.4 \mathrm{mmol} \mathrm{L}^{-1}$.

In general, the anaerobic bacteria under study could tolerate more CF and 1,2-DCA than PCE and CT (Fig. 1C and 1D). With the exception of $G$. sulfurreducens and $D$. vulgaris, all microorganisms displayed $\mathrm{EC}_{50}$ values for $\mathrm{CF}$ above $3.5 \mathrm{mmol} \mathrm{L}^{-1}$. G. sulfurreducens showed an $\mathrm{EC}_{50}$ for CF of $0.2 \mathrm{mmol} \mathrm{L}^{-1}$, while D. vulgaris was the organism most sensitive to $\mathrm{CF}$ and was completely inhibited even at the lowest test concentration of $0.2 \mathrm{mmol} \mathrm{L}^{-1}$. All eight lineages could tolerate more 1,2-DCA in the medium than any other solvent, $\mathrm{EC}_{50}$ values being consistently above $6.5 \mathrm{mmol} \mathrm{L}^{-1}$ (Fig. 1D). G. sulfurreducens and D. vulgaris could still grow at $70 \%$ and $91 \%$ of $\mu_{0}$ at the respective highest 1,2-DCA levels tested of 3.72 and $4.65 \mathrm{mmol} \mathrm{L}^{-1}$, and while an $\mathrm{EC}_{50}$ of $6.5 \mathrm{mmol} \mathrm{L}^{-1}$ could be calculated by extrapolation for $G$. sulfurreducens, it could not be calculated for $D$. vulgaris 

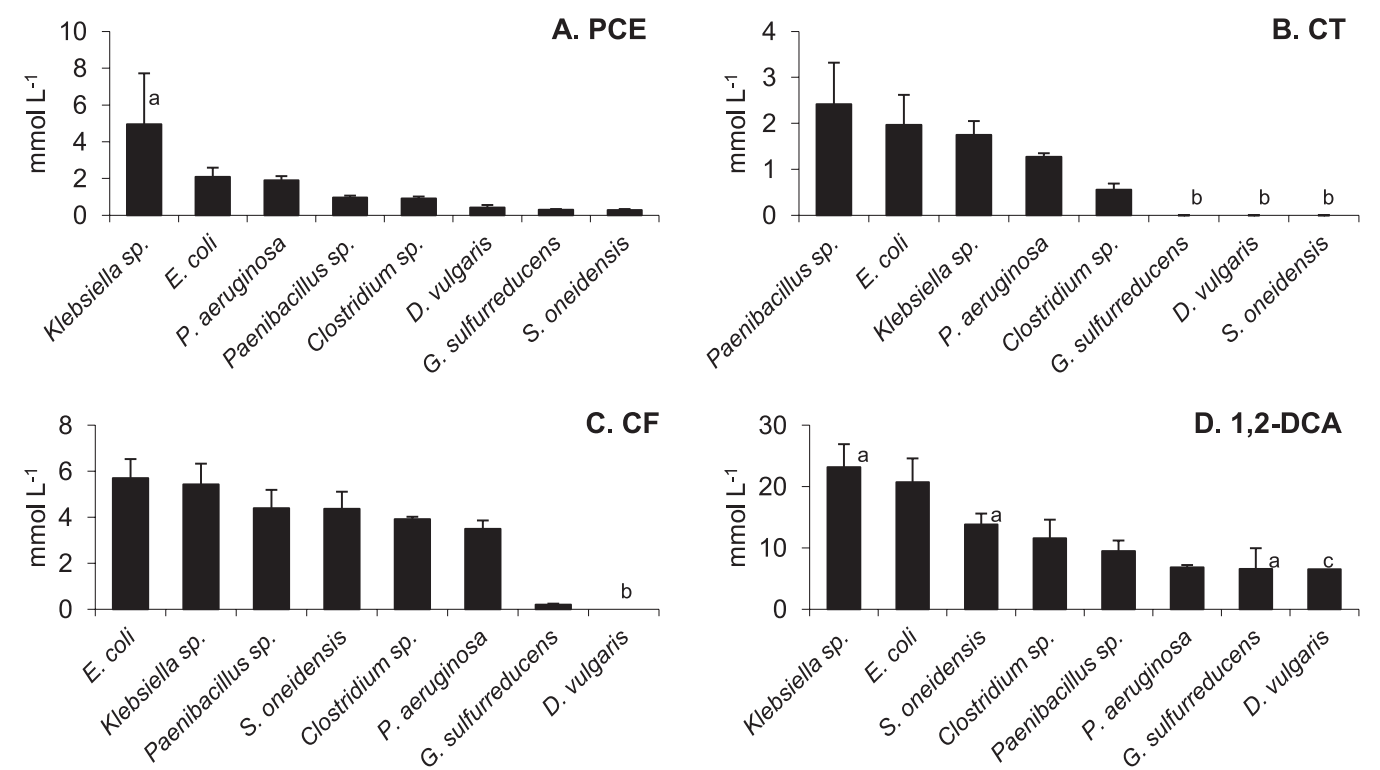

Fig. 1. Concentrations of chlorinated solvents which inhibit growth rates by $50 \%\left(\mathrm{EC}_{50}\right)$. $\mathrm{PCE}$ concentrations above $0.9 \mathrm{mmol} \mathrm{L}^{-1}$ are nominal and indicate the presence of free-phase PCE. Values are averages of triplicates; error bars represent one standard deviation. ${ }^{a}$ Value obtained by extrapolation using linear trend line; bo growth occurred at the lowest solvent level tested; ' ${ }^{\mathrm{c}}$ Desulfovibrio vulgaris tolerated far above the highest level of 1,2-DCA tested $\left(4.65 \mathrm{mmol} \mathrm{L}^{-1}\right)$ and was assigned the same $\mathrm{EC}_{50}$ as Geobacter sulfurreducens.

given the lack of a decreasing trend of growth rate versus 1,2-DCA. Because D. vulgaris was at least as tolerant to 1,2DCA as G. sulfurreducens, a minimum $\mathrm{EC}_{50}$ of $6.5 \mathrm{mmol} \mathrm{L}^{-1}$ is reported for this species. Overall, the most solvent-tolerant anaerobic bacteria were Klebsiella sp. and E. coli, consistently appearing in the top three highest $\mathrm{EC}_{50}$ values for any of the four solvents tested. The least tolerant organisms were D. vulgaris and G. sulfurreducens.

The ability of a species to tolerate CAHs, as given by $\mathrm{EC}_{50}$, correlated well with its growth rate in solvent-free cultures, $\mu_{0}$ (Fig. 2). Coefficients of determination for linear regressions fitted to the data were above 0.7 for all solvents except CT (Fig. 2B), validating growth rate as an important parameter influencing bacterial solvent tolerance. In the case of $\mathrm{CT}$, the ability of a species to grow rapidly under stress-free conditions did not influence its capacity to tolerate the chlorinated compound, as it did with the other three CAHs. Nevertheless, when scoring a species' solvent tolerance by normalizing and averaging its $\mathrm{EC}_{50}$ values across all four CAHs, a very good correlation appears between the maximum growth rate and tolerance $\left(R^{2}=0.89\right.$, Fig. $\left.2 \mathrm{E}\right)$. Slowgrowing organisms such as $G$. sulfurreducens and $D$. vulgaris were the most sensitive overall, while fast-growing species such as Klebsiella sp. and E. coli demonstrated marked resistance to CAH toxicity.

When considering individual CAHs, a good correlation could be found between a compound's hydrophobicity, as denoted by its $\log \mathrm{P}_{\mathrm{o} / \mathrm{w}}$, and its ability to inhibit bacterial growth (Fig. 3). For all eight bacterial lineages tested, 1,2DCA $\left(\log \mathrm{P}_{\mathrm{o} / \mathrm{w}}=1.48\right)$ was consistently less toxic than $\mathrm{CF}$ $\left(\log \mathrm{P}_{\mathrm{o} / \mathrm{w}}=1.97\right), \mathrm{CT}\left(\log \mathrm{P}_{\mathrm{o} / \mathrm{w}}=2.64\right)$ and PCE $\left(\log \mathrm{P}_{\mathrm{o} / \mathrm{w}}=\right.$ 2.88). For all but two species, $\mathrm{CF}$ was less toxic than $\mathrm{CT}$ and PCE, the exceptions to this rule being the two respiring species $G$. sulfurreducens and D. vulgaris. The delineation between CT and PCE was less clear. Except for Paenibacillus sp. and despite a marginally lower $\log \mathrm{P}_{\mathrm{o} / \mathrm{w}}, \mathrm{CT}$ was consistently more toxic than PCE, as it took less CT to diminish growth rates by half than PCE. Of particular note is the severe impact of CT on the three respiring strains $S$. oneidensis, $G$. sulfurreducens and D. vulgaris, which showed no growth at all at or below $80 \mu \mathrm{M}$.

\section{Discussion}

The rapid and complete bioremediation of CAHs in soil and groundwater hinges on the capacity of the bacteria involved to tolerate high concentrations of these solvents. Depending on the solvents present and on the cleanup protocol to be implemented, one or several anaerobic genera can be selected as detoxifying agents. Very few reports concerning the solvent tolerance of anaerobic bacteria are available, which represents a gap in the bioremediation knowledge base. In this report, the CAH tolerance of fermenting, iron-, sulfate-, nitrate- and fumarate-reducing bacterial species was studied.

Studies on the sensitivity of aerobic bacteria to solvents have led to an empirical rule concerning solvent toxicity, stating that a bacterium can grow with a free phase of any solvent with a $\log \mathrm{P}_{\mathrm{o} / \mathrm{w}}$ above that of the index value, equivalent to the $\log \mathrm{P}_{\mathrm{o} / \mathrm{w}}$ of the most toxic solvent tolerated $(6,7$, 28 ). Solvents with $\log \mathrm{P}_{\mathrm{o} / \mathrm{w}}$ below the index value are too toxic to allow growth when present as a free phase.

Results of the current study support the validity of this rule for anaerobic bacteria. The CAH with the highest $\log \mathrm{P}_{\mathrm{o} / \mathrm{w}}$ was PCE, and five out of eight species tolerated the presence of a small volume of free-phase PCE, indicated by $\mathrm{EC}_{50}$ values above the solubility of PCE $\left(0.9 \mathrm{mmol} \mathrm{L}^{-1}\right)$. No species could tolerate the presence of free phases of any of the other three CAHs with lower $\log \mathrm{P}_{\mathrm{o} / \mathrm{w}}$. While $\mathrm{EC}_{50}$ values for the more polar CF and 1,2-DCA were higher than for the less polar 


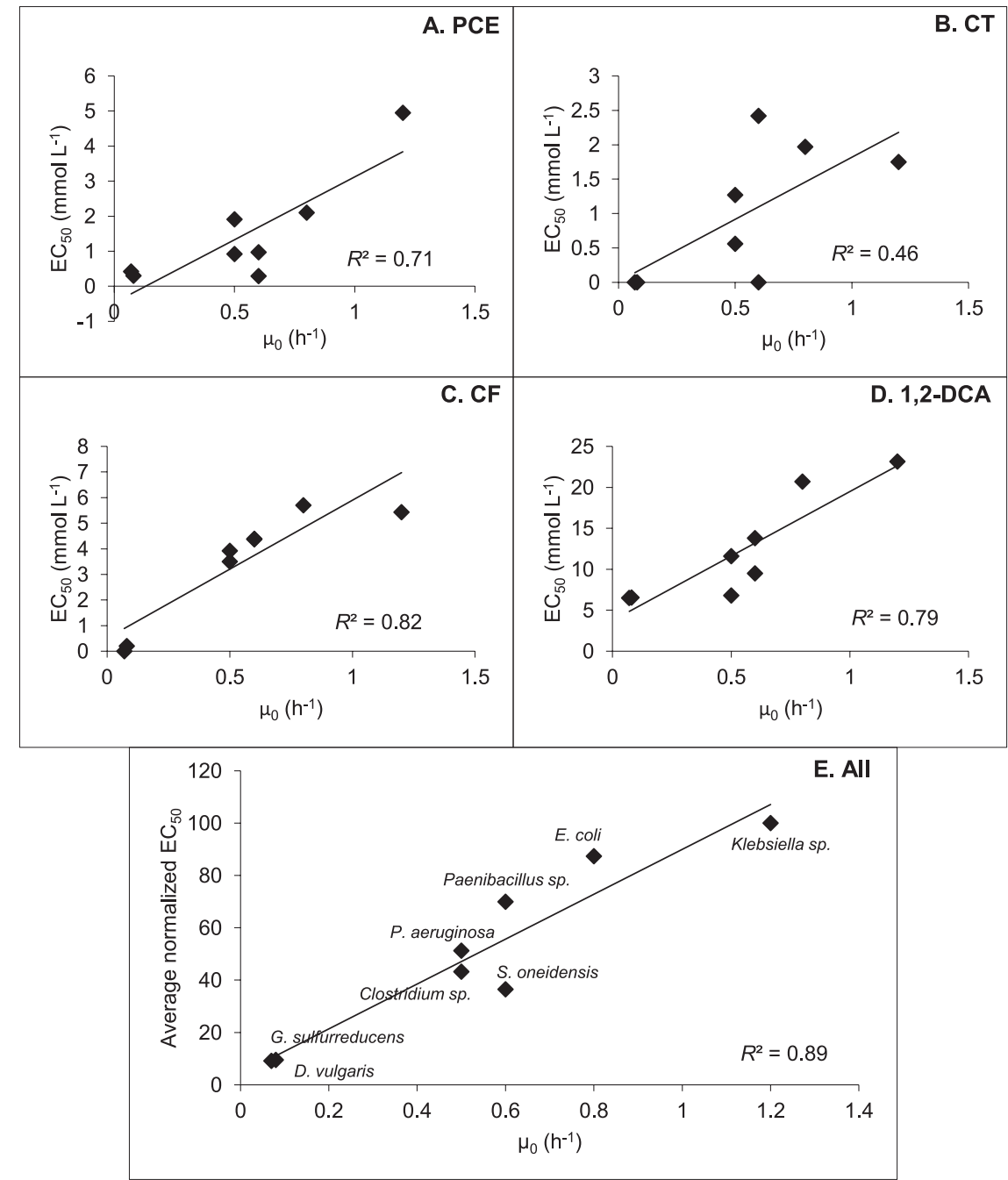

Fig. 2. Relationship between no-solvent growth rate $\left(\mu_{0}\right)$ and $\mathrm{EC}_{50}$. Panel $\mathrm{E}$ comprises a plot of species' averaged normalized $\mathrm{EC}_{50} \mathrm{~s}$ versus nosolvent growth rates. Normalization was carried out by setting the $\mathrm{EC}_{50}$ of Klebsiella sp. at $100 \%$ for each solvent and expressing $\mathrm{EC}_{50} \mathrm{~s}$ for all other species as percentages of Klebsiella's $\mathrm{EC}_{50}$. All four values for each species were then averaged.

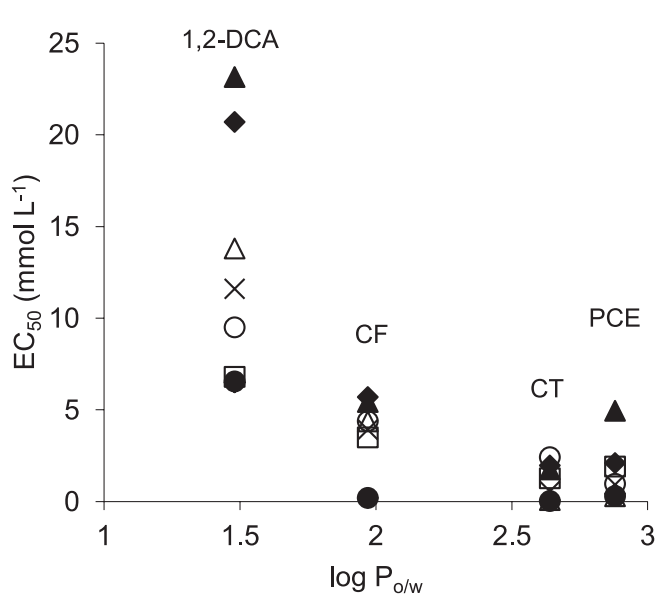

Fig. 3. Relationship between $\mathrm{EC}_{50}$ and $\mathrm{CAH} \log \mathrm{P}_{\mathrm{o} / \mathrm{w}}$ (dimensionless) for each species. $\log \mathrm{P}_{\mathrm{o} / \mathrm{w}}$ values were obtained from (35): 1,2-DCA: 1.48; CF: 1.97; CT: 2.64; PCE: 2.88. Legend: $\bullet$ E. coli; $\square$ P. aeruginosa; $\Delta$ Klebsiella sp.; × Clostridium sp.; ○ Paenibacillus sp.; $\bullet$ G. sulfurreducens; $\diamond D$. vulgaris; $\Delta$ S. oneidensis.
$\mathrm{CT}$ and $\mathrm{PCE}$, these $\mathrm{EC}_{50}$ values actually represent smaller percentages of the solvents' maximum aqueous solubility. The average $\mathrm{EC}_{50}$ for $\mathrm{CT}$ was $1 \mathrm{mmol} \mathrm{L}^{-1}$, equivalent to $20 \%$ of CT solubility, while average $\mathrm{EC}_{50} \mathrm{~s}$ for $\mathrm{CF}$ and 1,2-DCA were 3.5 and $12.3 \mathrm{mmol} \mathrm{L}^{-1}$, equating to 5 and $14 \%$ of maximum solubility respectively. This indicates that, overall, the anaerobic bacteria tested would be less able to grow with free phases of more polar than less polar compounds. This has implications for the bioremediation of solvents present as DNAPL, suggesting that more polar solvents such as 1,2DCA are less likely to be tolerated as free phases than as dissolved plumes. With less polar compounds such as PCE, the likelihood of bacteria establishing themselves near DNAPL is higher, leading to faster dissolution times as degradation proceeds (12).

The increased toxicity of PCE to bacteria beyond its aqueous solubility threshold observed here reflects phenomena noted by other authors $(9,56)$. One potential explanation involves direct contact between cells and free-phase solvent increasing as the number and size of solvent droplets increased (56), thereby amplifying solvent partitioning in 
membranes and causing cell death.

Despite CT having a $\log \mathrm{P}_{\mathrm{o} / \mathrm{w}}$ similar to that of PCE, it was more toxic than PCE for most species examined. The higher aqueous solubility limit of CT possibly accounts for this divergence. While PCE forms a free phase above $0.9 \mathrm{mmol}$ $\mathrm{L}^{-1}, \mathrm{CT}$ 's aqueous solubility is $5 \mathrm{mmol} \mathrm{L}^{-1}$, meaning greater dissolved levels of CT can cause stress to bacterial cells before a separate phase is formed. Between 0.9 and $5 \mathrm{mmol}$ $\mathrm{L}^{-1}$, where many $\mathrm{EC}_{50} \mathrm{~s}$ are found, $\mathrm{CT}$ presents a much greater threat to cell integrity compared with PCE, by still existing in the dissolved form while being almost as hydrophobic as PCE.

In terms of solvent tolerance, the eight anaerobes investigated here can be classified into three groups. Firstly, the two fermenters E. coli and Klebsiella sp. displayed the highest resistance to $\mathrm{CAH}$ stress. They belong to the family Enterobacteriaceae of the class Gammaproteobacteria, are facultatively anaerobic, and were also the fastest growing bacteria tested. In the second category are the other two fermenting species Clostridium sp. and Paenibacillus sp., both belonging to the phylum Firmicutes, together with the two other Gammaproteobacteria P. aeruginosa and $S$. oneidensis. These four species displayed intermediate growth rates and $\mathrm{EC}_{50}$ values. In the third category are the two Deltaproteobacteria G. sulfurreducens and D. vulgaris, the most CAH-sensitive species in this investigation and also the slowest growing and only strictly anaerobic respiring species.

When comparing $\mathrm{EC}_{50}$ values obtained in this study with those given in the literature for aerobic bacteria, tolerance levels appear similar between aerobes and the fast-growing anaerobes of the first two groups outlined above. In a study by Heipiepier et al. (26), $\mathrm{EC}_{50} \mathrm{~s}$ of 3.6 and $3.2 \mathrm{mmol} \mathrm{L}^{-1}$ were reported for aerobic Pseudomonas putida exposed to toluene and styrene, two solvents with $\log \mathrm{P}_{\mathrm{o} / \mathrm{w}}$ of 2.48 and 3.0, respectively. Hage et al. reported $\mathrm{EC}_{50} \mathrm{~s}$ of 8.0, 13.0, 1.5, 3.0, 0.5 and $1.9 \mathrm{mmol} \mathrm{L}^{-1}$ for P. putida growing in the presence of various organic compounds with $\log \mathrm{P}_{\mathrm{o} / \mathrm{w}}$ in the range 1.72 3.46 (25). Another aerobe, Acinetobacter calcoaceticus, showed $\mathrm{EC}_{50} \mathrm{~s}$ of between 6.0 and $0.11 \mathrm{mmol} \mathrm{L}^{-1}$ when exposed to alkanols of $\log \mathrm{P}_{\mathrm{o} / \mathrm{w}}$ of between 1.87 and 3.97, with $\mathrm{EC}_{50} \mathrm{~s}$ decreasing with increasing $\log \mathrm{P}_{\mathrm{o} / \mathrm{w}}$ (30). In this study, most bacteria tested showed $\mathrm{EC}_{50} \mathrm{~s}>0.5-23 \mathrm{mmol} \mathrm{L}^{-1}$ with solvents of $\log \mathrm{P}_{\mathrm{o} / \mathrm{w}}$ of 1.48-2.88. Hence, we conclude that anaerobic bacteria can be at least as tolerant as aerobic bacteria, depending on metabolism and growth rate.

The apparent relationship between growth rate and $\mathrm{CAH}$ tolerance could be explained by a high turnover of cell components in fast-growing species compensating for the damage inflicted through contact with CAHs. Further, a number of solvent tolerance mechanisms elucidated in Gram-negative bacteria, such as changes in membrane fatty acid composition and production of stress proteins, require de novo synthesis, strongly linked to cell growth $(30,32,46)$. Gram-negative bacteria have also been shown to possess energy-dependent solvent efflux pumps $(31,54)$, pointing to energy status as an important factor in solvent resistance. In Gram-positive bacteria, changes in membrane composition and the appearance of stress proteins have also been demonstrated $(3,51)$. The sensitivity of slow-growing organisms in this study is likely linked to lower energy generation rates, leading to a delay in resistance mechanism activation and thus greater vulnerability to solvent attack. Duldhardt et al. (19) recently demonstrated that the anaerobic respirers $G$. sulfurreducens, Desulfococcus multivorans and Thauera aromatica respond to solvent toxicity through increases in the saturated fatty acid component of their cell membranes, a mechanism dependent on cell growth.

The compound CT was particularly toxic to $G$. sulfurreducens, $D$. vulgaris and $S$. oneidensis. When comparing $\mathrm{EC}_{50}$ values obtained for G. sulfurreducens and $D$. multivorans in a study by Duldhardt et al. (18) to those obtained here for $G$. sulfurreducens and $D$. vulgaris, close similarities are found for chlorinated and non-chlorinated solvents of similar $\log \mathrm{P}_{\mathrm{o} / \mathrm{w}}$. For instance, $\mathrm{EC}_{50} \mathrm{~s}$ for 1,2-DCA of $6.5 \mathrm{mmol} \mathrm{L}^{-1}$ obtained here approximate the $\mathrm{EC}_{50} \mathrm{~s}$ of 7.6 to $8.9 \mathrm{mmol} \mathrm{L}^{-1}$ obtained by Duldhardt et al. for phenol, which has the same $\log \mathrm{P}_{\mathrm{o} / \mathrm{w}}$ as 1,2-DCA $\left(\log \mathrm{P}_{\mathrm{o} / \mathrm{w}}=1.48\right)$. Also, $\mathrm{EC}_{50} \mathrm{~s}$ of $0.3-0.4 \mathrm{mmol} \mathrm{L}^{-1}$ were determined here for PCE $\left(\log \mathrm{P}_{\mathrm{o} / \mathrm{w}}=2.88\right)$ compared with $\mathrm{EC}_{50} \mathrm{~s}$ of $0.1-0.2 \mathrm{mmol}$ $\mathrm{L}^{-1}$ for solvents of $\log \mathrm{P}_{\mathrm{o} / \mathrm{w}}$ near 3.0, such as 1-octanol and ethylbenzene, found by Duldhardt et al. The same correspondence, however, did not apply to CT and CF and non-chlorinated compounds with similar $\log \mathrm{P}_{\mathrm{o} / \mathrm{w}}$ values, suggesting that $\mathrm{CT}$ and $\mathrm{CF}$ have additional distinct mechanisms of toxicity. A specific toxicity mechanism has previously been reported for CT, with the formation of radicals from CT interacting with reduced bacterial proteins and co-factors $(14,42)$. This is termed "reactive toxicity" and solvents which cause this type of toxicity do not fit models based on properties such as $\log \mathrm{P}_{\mathrm{o} / \mathrm{w}}(9,44)$. It is possible that electron chain components located in the cell membrane of respiring bacteria are more vulnerable to this toxic action than cytoplasm-based energy generation through fermentation. The toxicity of CT and CF to organohalide-respiring bacteria such as Dehalococcoides is well-documented (17, 41 , suggesting the general susceptibility of anaerobic respiring bacteria to these compounds.

The nitrate respirer $P$. aeruginosa, despite possessing an electron chain, was not more susceptible to CT or CF than other solvents. Its high growth rate coupled with the wellknown ability of Pseudomonas species to tolerate organic solvents in general (46) likely account for this exception. Moreover, the sensitivity of electron transport chain proteins to solvents might differ between nitrate respiration and other respiration pathways and is worthy of further research efforts.

Of note are the two fermenting bacteria Clostridium sp. strain BIP1 and Paenibacillus sp. strain BIP2, both isolated from a CAH-contaminated aquifer as part of this study. Several members of the Clostridia have been found to be associated with organochlorine-respiring bacteria (ORB) in dechlorinating cultures, where they are thought to participate in substrate fermentation and hydrogen supply to the ORB $(22,23,50)$. Bowman et al. (11) tested the effects of 1,2-DCA and PCE on hydrogen production by 18 strains of Clostridium isolated from $\mathrm{CAH}$-contaminated groundwater, and inhibitory concentrations fit well with $\mathrm{EC}_{50}$ values obtained here for Clostridium sp. strain BIP1. Interestingly, the 16S rRNA gene of strain BIP1 most closely matched Clostridium sp. strain BL-26 isolated by Bowman et al., and it was also isolated from acidic (pH 3.5 to 5.8) CAH-contaminated 
groundwater, suggesting that similar strains of Clostridium sp. may exist in acidic chlorinated solvent-polluted groundwater sites around the world. The Paenibacillus sp. strain examined here was isolated from the same contaminated site and was the most CT-tolerant bacterium amongst all those tested. It is possible that long-term in situ exposure to DNAPL comprising CT led to the increased tolerance of this organism. The potential of these groundwater-dwelling bacteria to act as hydrogen providers, together with their relatively high $\mathrm{CAH}$ tolerance compared with respiring species, suggests that encouraging the co-existence of fermenting and respiring species may have advantages over the stimulation of respiring species only in bioremediation strategies.

In summary, the data presented indicate that anaerobic bacteria are sensitive to CAHs, and their level of toxicity can generally be predicted by their $\log \mathrm{P}_{\mathrm{o} / \mathrm{w}}$. However, $\log \mathrm{P}_{\mathrm{o} / \mathrm{w}}$ is not always a reliable indicator and other parameters such as aqueous solubility and potential for reactive toxicity need to be evaluated when assessing the impact of CAH contamination in an aquifer or planning a bioremediation strategy. Fast-growing bacteria, especially fermenters, were found to be more tolerant overall than slow-growing anaerobic respiring bacteria, likely due to their capacity to rapidly activate energy-dependent resistance mechanisms. Efforts are underway in our laboratory to further elucidate possible links between growth rate and solvent tolerance. Bioremediation protocols would benefit from including fermenting organisms in their CAH detoxification plan, as not only can they often degrade contaminants through cometabolism but also new ways of harvesting the reducing power they liberate from organic carbon are continuously being discovered (53). Moreover, fermenting bacteria can provide substrates and co-factors to organochlorine-, sulfate- and iron-reducing bacteria, which affect $\mathrm{CAH}$ dechlorination directly through enzymatic action or through the production of redox-active $\mathrm{Fe}(\mathrm{II})$ and sulfide minerals. The higher sensitivity of IRB and SRB shown here must be considered when these organisms are chosen as biocatalysts: the location of $\mathrm{Fe}(\mathrm{II})$ and/or sulfide-rich zones at contaminated sites for $\mathrm{CAH}$ treatment is likely to be most successful down-gradient of DNAPL zones, where solvent concentrations can be tolerated without compromising the rate or extent of treatment. Whether fermenting bacteria can enhance this process is worthy of further research.

\section{Acknowledgements}

This work was carried out thanks to funding provided by Orica Australia Pty Ltd and The Australian Research Council, Grant number LP0669801.

\section{References}

1. Adamson, D.T., J.M. McDade, and J.B. Hughes. 2003. Inoculation of a DNAPL source zone to initiate reductive dechlorination of PCE. Environ. Sci. Technol. 37:2525-2533.

2. AFCEE (Air Force Center for Environmental Excellence). 2004. Principles and practices of enhanced anaerobic bioremediation of chlorinated solvents. Online at www.costperformance.org/ remediation/pdf/principles_and_practices_bioremediation.pdf, accessed 31 July 2013.
3. Alsaker, K.V., C. Paredes, and E.T. Papoutsakis. 2010. Metabolite stress and tolerance in the production of biofuels and chemicals: gene-expression-based systems analysis of butanol, butyrate, and acetate stresses in the anaerobe Clostridium acetobutylicum. Biotechnol. Bioeng. 105:1131-1147.

4. Altschul, S.F., W. Gish, W. Miller, E.W. Myers, and D.J. Lipman. 1990. Basic local alignment search tool. J. Mol. Biol. 215:403-410.

5. Amos, B.K., J.A. Christ, L.M. Abriola, K.D. Pennell, and F.E. Löffler. 2007. Experimental evaluation and mathematical modeling of microbially enhanced tetrachloroethene (PCE) dissolution. Environ. Sci. Technol. 41:963-970.

6. Aono, R. 1998. Improvement of organic solvent tolerance level of Escherichia coli by overexpression of stress-responsive genes. Extremophiles 2:239-248.

7. Aono, R., N. Tsukagoshi, and T. Miyamoto. 2001. Evaluation of the growth inhibition strength of hydrocarbon solvents against Escherichia coli and Pseudomonas putida grown in a two-liquid phase culture system consisting of a medium and organic solvent. Extremophiles 5:11-15.

8. ATSDR (Agency for Toxic Substances and Disease Registry). 2011. Cercla priority list of hazardous substances. Online at www.atsdr.cdc. gov/SPL/index.html, accessed 31 July 2013.

9. Blum, D.J.W., and R.E. Speece. 1991. Quantitative structure-activity relationships for chemical toxicity to environmental bacteria. Ecotox. Environ. Safe. 22:197-224.

10. Borden, J.R., and E.T. Papoutsakis. 2007. Dynamics of genomiclibrary enrichment and identification of solvent tolerance genes for Clostridium acetobutylicum. Appl. Environ. Microbiol. 73:30613068.

11. Bowman, K.S., F.A. Rainey, and W.M. Moe. 2009. Production of hydrogen by Clostridium species in the presence of chlorinated solvents. FEMS Microbiol. Lett. 290:188-194.

12. Carr, C.S., S. Garg, and J.B. Hughes. 2000. Effect of dechlorinating bacteria on the longevity and composition of PCE-containing nonaqueous phase liquids under equilibrium dissolution conditions. Environ. Sci. Technol. 34:1088-1094.

13. Criddle, C.S., J.T. DeWitt, D. Grbic-Galic, and P.L. McCarty. 1990. Transformation of carbon tetrachloride by Pseudomonas sp. strain KC under denitrification conditions. Appl. Environ. Microbiol. 56:32403246.

14. Criddle, C.S., J.T. DeWitt, and P.L. McCarty. 1990. Reductive dehalogenation of carbon tetrachloride by Escherichia coli K12. Appl. Environ. Microbiol. 56:3247-3254.

15. deBest, J.H., E. Salminen, H.J. Doddema, D.B. Janssen, and W. Harder. 1998. Transformation of carbon tetrachloride under sulfate reducing conditions. Biodegradation 8:429-436.

16. Dong, Y., X. Liang, L.R. Krumholz, R.P. Philp, and E.C. Butler. 2009. The relative contributions of abiotic and microbial processes to the transformation of tetrachloroethylene and trichloroethylene in anaerobic microcosms. Environ. Sci. Technol. 43:690-697.

17. Duhamel, M., S.D. Wehr, L. Yu, H. Rizvi, D. Seepersad, S. Dworatzek, E.E. Cox, and E.A. Edwards. 2002. Comparison of anaerobic dechlorinating enrichment cultures maintained on tetrachloroethene, trichloroethene, cis-dichloroethene and vinyl chloride. Water Res. 36:4193-4202.

18. Duldhardt, I., I. Nijenhuis, F. Schauer, and H.J. Heipieper. 2007. Anaerobically grown Thauera aromatica, Desulfococcus multivorans, Geobacter sulfurreducens are more sensitive towards organic solvents than aerobic bacteria. Appl. Microbiol. Biotechnol. 77:705-711.

19. Duldhardt, I., J. Gaebel, L. Chrzanowski, I. Nijenhuis, C. Hartig, F. Schauer, and H.J. Heipieper. 2010. Adaptation of anaerobically grown Thauera aromatica, Geobacter sulfurreducens and Desulfococcus multivorans to organic solvents on the level of membrane fatty acid composition. Microbial Biotech. 3:201-209.

20. Fernandes, P., B.S. Ferreira, and J.M. Sampaio Cabral. 2003. Solvent tolerance in bacteria: role of efflux pumps and cross-resistance with antibiotics. Int. J. Antimicrob. Ag. 22:211-216.

21. Field, J.A., and R. Sierra-Alvarez. 2004. Biodegradability of chlorinated solvents and related chlorinated aliphatic compounds. Rev. Environ. Sci. Biotechnol. 3:185-254

22. Fletcher, K.E., K.M. Ritalahti, K.D. Pennell, K. Takamizawa, and F.E. Löffler. 2008. Resolution of culture Clostridium bifermentans DPH-1 into two populations, a Clostridium sp and tetrachloroethenedechlorinating Desulfitobacterium hafniense strain JH1. Appl. Environ. Microbiol. 74:6141-6143. 
23. Grostern, A., and E.A. Edwards. 2009. Characterization of a Dehalobacter coculture that dechlorinates 1,2-dichloroethane to ethene and identification of the putative reductive dehalogenase gene. Appl. Environ. Microbiol. 75:2684-2693.

24. Grostern, A., M. Duhamel, S. Dworatzek, and E.A. Edwards. 2010. Chloroform respiration to dichloromethane by a Dehalobacter population. Environ. Microbiol. 12:1053-1060.

25. Hage, A., H.E. Schoemaker, R. Wever, E. Zennaro, and H.J. Heipieper. 2001. Determination of the toxicity of several aromatic carbonylic compounds and their reduced derivatives on Phanerochaete chrysosporium using a Pseudomonas putida test system. Biotechnol. Bioeng. 73:69-73.

26. Heipieper, H.J., F.J. Weber, J. Sikkema, H. Keweloh, and J.A.M. De Bont. 1994. Mechanisms of resistance of whole cells to toxic organic solvents. Trends Biotechnol. 12:409-415.

27. Heipieper, H.J., G. Neumann, S. Cornelissen, and F. Meinhardt. 2007. Solvent-tolerant bacteria for biotransformations in two-phase fermentation systems. Appl. Microbiol. Biotechnol. 74:961-973.

28. Inoue, A., and K. Horikoshi. 1991. Estimation of solvent-tolerance of bacteria by the solvent parameter log P. J. Ferment. Bioeng. 71:194196.

29. Isken, S., and J.A.M. de Bont. 1998. Bacteria tolerant to organic solvents. Extremophiles 2:229-238.

30. Kabelitz, N., P.M. Santos, and H.J. Heipieper. 2003. Effect of aliphatic alcohols on growth and degree of saturation of membrane lipids in Acinetobacter calcoaceticus. FEMS Microbiol. Lett. 220:223-227.

31. Kieboom, J., J.J. Dennis, J.A.M. de Bont, and G.J. Zylstra. 1998. Identification and molecular characterization of an efflux pump involved in Pseudomonas putida S12 solvent tolerance. J. Biol. Chem. 273:85-91.

32. Kobayashi, H., M. Yamamoto, and R. Aono. 1998. Appearance of a stress-response protein, phage-shock protein A, in Escherichia coli exposed to hydrophobic organic solvents. Microbiol-SGM 144:353359.

33. Koenig, J.C., M.J. Lee, and M. Manefield. 2012. Successful microcosm demonstration of a strategy for biodegradation of a mixture of carbon tetrachloride and perchloroethene harnessing sulfate reducing and dehalorespiring bacteria. J. Hazard. Mater. 219-220:169-175.

34. Lane, D.J. 1991. 16S/23S rRNA sequencing, p. 115-175. In E. Stackebrandt and M. Goodfellow (ed.), Nucleic Acid Techniques in Bacterial Systematics. Wiley, New York.

35. Lide, D.R. 2011. CRC Handbook of Chemistry and Physics, 91st ed (Internet Version 2011). CRC Press/Taylor and Francis, Boca Raton.

36. Löffler, F.E., J.R. Cole, K.M. Ritalahti, and J. Tiedje. 2003. Diversity of dechlorinating bacteria, p. 53-87. In M.M. Haggblom and I.D. Bossert (ed.), Dehalogenation: Microbial Processes and Environmental Applications. Kluwer Academic, New York.

37. Löffler, F.E., R.A. Sanford, and K.M. Ritalahti. 2005. Enrichment, cultivation, and detection of reductively dechlorinating bacteria, $\mathrm{p}$. 77-111. In J.R. Leadbetter (ed.), Environmental Microbiology, vol. 397. Elsevier Academic Press, San Diego.

38. Löffler, F.E., and E.A. Edwards. 2006. Harnessing microbial activities for environmental cleanup. Curr. Opin. Biotech. 17:274-284.

39. Maithreepala, R.A., and R.A. Doong. 2009. Transformation of carbon tetrachloride by biogenic iron species in the presence of Geobacter sulfurreducens and electron shuttles. J. Hazard. Mater. 164:337-344.

40. Maymó-Gatell, X., T. Anguish, and S.H. Zinder. 1999. Reductive dechlorination of chlorinated ethenes and 1,2-dichloroethane by "Dehalococcoides ethenogenes" 195. Appl. Environ. Microbiol. 65:3108-3113.
41. Maymó-Gatell, X., I. Nijenhuis, and S.H. Zinder. 2001. Reductive dechlorination of cis-1,2-dichloroethene and vinyl chloride by "Dehalococcoides ethenogenes". Environ. Sci. Technol. 35:516-521.

42. McCormick, M.L., E.J. Bouwer, and P. Adriaens. 2002. Carbon tetrachloride transformation in a model iron-reducing culture: relative kinetics of biotic and abiotic reactions. Environ. Sci. Technol. $36: 403-410$.

43. McCormick, M.L., and P. Adriaens. 2004. Carbon tetrachloride transformation on the surface of nanoscale biogenic magnetite particles. Environ. Sci. Technol. 38:1045-1053.

44. Nirmalakhandan, N., E. Egemen, C. Trevizo, and S. Xu. 1998. Structure- and property-activity relationship models for prediction of microbial toxicity of organic chemicals to activated sludge. Ecotox. Environ. Safe. 39:112-119.

45. Panesar, P.S., S.S. Marwaha, and J.F. Kennedy. 2006. Zymomonas mobilis: an alternative ethanol producer. J. Chem. Technol. Biot. 81:623-635.

46. Ramos, J.L., E. Duque, M.T. Gallegos, P. Godoy, M.I. RamosGonzalez, A. Rojas, W. Teran, and A. Segura. 2002. Mechanisms of solvent tolerance in gram-negative bacteria. Annu. Rev. Microbiol. $56: 743-768$.

47. Rojas, A., E. Duque, G. Mosqueda, G. Golden, A. Hurtado, J.L. Ramos, and A. Segura. 2001. Three efflux pumps are required to provide efficient tolerance to toluene in Pseudomonas putida DOTT1E. J. Bacteriol. 183:3967-3973.

48. Shan, H., H.D. Kurtz Jr, N. Mykytczuk, J.T. Trevors, and D.L. Freedman. 2010. Anaerobic biotransformation of high concentrations of chloroform by an enrichment culture and two bacterial isolates. Appl. Environ. Microbiol. 76:6463-6469.

49. Sikkema, J., J.A.M. de Bont, and B. Poolman. 1995. Mechanisms of membrane toxicity of hydrocarbons. Microbiol. Rev. 59:201-222.

50. Sung, Y., K.M. Ritalahti, R.A. Sanford, J.W. Urbance, S.J. Flynn, J.M. Tiedje, and F.E. Löffler. 2003. Characterization of two tetrachloroethene-reducing, acetate-oxidizing anaerobic bacteria and their description as Desulfuromonas michiganensis sp. nov. Appl. Environ. Microbiol. 69:2964-2974.

51. Tomas, C.A., N.E. Welker, and E.T. Papoutsakis. 2003. Overexpression of groESL in Clostridium acetobutylicum results in increased solvent production and tolerance, prolonged metabolism, and large changes in the cell's transcriptional program. Appl. Environ. Microbiol. 69:4951-4965.

52. USEPA. 2000. Engineered approaches to in situ bioremediation of chlorinated solvents: fundamentals and field applications; EPA 542R-00-008. Washington, D.C.

53. Watanabe, K., M. Manefield, M.J. Lee, and A. Kouzuma. 2009. Electron shuttles in biotechnology. Curr. Opin. Biotech. 20:633-641.

54. White, D.G., J.D. Goldman, B. Demple, and S. Levy. 1997. Role of the $a c r A B$ locus in organic solvent tolerance mediated by expression of marA, soxS, or robA in Escherichia coli. J. Bacteriol. 179:61226126.

55. Yang, Y.Y., and P. McCarty. 2000. Biologically enhanced dissolution of tetrachloroethene DNAPL. Environ. Sci. Technol. 34:2979-2984.

56. Zahir, Z., K.D. Seed, and J.J. Dennis. 2006. Isolation and characterization of novel organic solvent-tolerant bacteria. Extremophiles 10:129-138.

57. Zheng, Z., S. Schwartz, L. Wagner, and W. Miller. 2000. A greedy algorithm for aligning DNA sequences. J. Comput. Biol. 7:203-214. 